\title{
Analysis of Teaching Methods for Auditing Based on the Cultivation of Application-oriented Talents
}

\author{
Haihong Qiu \\ The school of Finance and Economics, Xizang Minzu University, Xianyang 712082, Shaanxi China \\ qiuhaihonghh@163.com
}

Keywords: Application-oriented talents; Auditing teaching; Case teaching method; Simulating experiment teaching method; Practical teaching method

\begin{abstract}
Auditing, as the main course of accounting specialty, is a challenge to teach because of its thinking mode different to other accounting course. It is a long-time plagued problem in auditing teaching due to the teacher finding it hard to teach, and students finding it hard to learn. The author analyses and compares the advantage and disadvantage of the case teaching method, simulating experiment teaching method and practical teaching method. And the author chose a new method that is uniform the three methods organically. The result shows that using these methods uniformly help students understand and master auditing course knowledge and improve students' study interest and enthusiasm. Meanwhile it also could increase the students' practical experience, and enhance the students' capacity of doing it by hand.
\end{abstract}

\section{Introduction}

According to the requirements of higher educational curriculum in our country, auditing is one of the main courses in the science of accounting science system, just as accounting, financial accounting, financial management, cost accounting. There is a problem which teachers and students always puzzled, that is teacher finding hard to teach and students finding difficultly to learn during auditing teaching processes. So it is very important on how to improve the auditing teaching effect, cultivate students' knowledge and the ability of solving practical problems, improve audit to learn the way of teaching.

There are many teaching methods on auditing teaching processes, such as case teaching method, simulating experiment teaching, practical teaching method and so on. It has been found that these methods are very effective in ordinarily auditing teaching processes. But for cultivating application-oriented talents, it is urgently need the new methods to achieve the goal.

In this article, the author combined with many years practice on auditing teaching, will discuss and give some advices on how to improve auditing teaching effect aims at cultivating the applied talents.

\section{Methodology}

In order to present auditing teaching situation of objective evaluation, firstly we surveyed a simple questionnaire on 6 colleges, which has set up the auditing course of accounting undergraduate. The main content involves the teaching contents, teaching methods and teaching effects. The total sample was 508 people, and 494 valid questionnaires were received, which was more than $97 \%$. The result was shown in Table 1.

Secondly, we organized the survey the science of auditing teacher small symposium, the discussion, agree that audit teaching than accounting and financial management is difficult, and to ensure that the teaching effect need to spend more time and energy, and the teachers' teaching level and practice experience requirements are higher.

Finally, we came to the employing units to the audit professional social evaluation survey, further understand and realize, unit of choose and employ persons think student's beginning ability is bad, the actual audit work processes and methods are not familiar with, hard in a relatively short period of time to adapt to the requirements of the audit work. 
Table 1 The survey on auditing teaching

\begin{tabular}{|c|c|c|c|c|}
\hline NO. & Question & \multicolumn{3}{|c|}{ Answer } \\
\hline \multirow{2}{*}{1} & \multirow{2}{*}{ Are you interested in the audit course? } & Yes & No & Others \\
\hline & & $22.44 \%(114)$ & $58.46 \%(297)$ & $19.1 \%(97)$ \\
\hline \multirow{2}{*}{2} & \multirow{2}{*}{$\begin{array}{l}\text { Which factors influence you on audit learning } \\
\text { interest? }\end{array}$} & Methods & Contents & Others \\
\hline & & $82.08 \%(417)$ & $11.42 \%(58)$ & $19.1 \%(97)$ \\
\hline \multirow[t]{2}{*}{3} & \multirow{2}{*}{$\begin{array}{l}\text { How to mobilize the enthusiasm of learning } \\
\text { science of auditing? }\end{array}$} & $\begin{array}{l}\text { Increase vivid } \\
\text { case }\end{array}$ & $\begin{array}{l}\text { Strengthen the practice } \\
\text { teaching }\end{array}$ & Others \\
\hline & & $95.95 \%(487)$ & $79.92 \%(406)$ & $36.81 \%(187)$ \\
\hline
\end{tabular}

\section{Result and Discussion}

The Characteristic of Auditing. We believe that the reason for the problem puzzled teacher and students is lies in the science of auditing itself which is a typical applied discipline. It requires teachers should often participate in the actual auditing practice, from practicing to learn and to understand the auditing of the basic theory and basic methods, and using of practical experience to improve the audit theory and method of understanding. Then in the teaching process the teacher should take the point of view of practice and show the related theory and method to students, which can be understood and accepted conveniently. Moreover, the auditing is a kind of course which used reverse thinking. It is to solve the problem of how and why, which has great differences with other related course of accounting professional. Specific reflect in the following two aspects.

The Outstanding Character of Auditing is Comprehensiveness and Practicality Which needs the Teacher has a Wide Breadth of General Knowledge. Comprehensiveness is mainly shown as including many courses such as accounting, management, statistics, information technology, etc. In addition, the auditors in the auditing process need use of economic law, tax law and other related knowledge integrally, which are greatly enriched the contents of auditing teaching. That also reflects obvious comprehensive characteristics of auditing course.

Practicality is another character of auditing, which requires the teacher should not only teach students in theory on what to do and how to do, but also should pay attention to lead the students did on simulation practice and simulated operation in the in the study courses ration. And it is also need that trained students' practical skills, improving the students' perceptual knowledge for the audit process and method, shorten the distance of the theory and practice.

In view of the audit course comprehensiveness and practicality characteristics, simple theoretical teaching is hard to make the students understand the audit learn logic and essence. On the one hand, the audit work is comprehensive that need to learn the contents of auditing covers a wide range and level complex, which not easy to grasp. Although learned accounting, management, statistics, and so on related discipline knowledge, but the students master the knowledge are often scattered and not systematical, which can't put the related principle applied to specific audit program. On the other hand, practicality means combined auditing theory and practice knowledge or will fall into the whirlpool of abstract, which caused the student the rejection and fear in emotions, so lose interest in learning.

The Comprehensive Contents Determine the Teaching Method of Auditing Diversity. Science of auditing courses can be roughly divided into science of auditing principles and certified public accountant audit practice. Audit theory part mainly introduces the basic idea of auditing and methods, including auditing environment, the audit goal, the audit plan, importance and audit risk, audit evidence, audit working papers, audit sampling basic knowledge. These theoretical knowledge involved in the concept is more, each concept and mutual infiltration between the parts, and between knowledge item and logic is not easy to understand, which lead to the students in the study often feel related concepts too trivial, on the whole is difficult to master science of auditing. On the other hand, audit procedures and methods are known as abstract, even if can understand related principles, and it is difficult to connect them with daily economic activities.

The Main Teaching Methods Case Teaching Method. The case teaching method originated in the Harvard Business School, and had a huge success in the MBA education of HBS. Case method 
is through the analysis of the typical case its interpretation, inspire the student to the case provides the objective facts and problem analysis, in order to improve the students' ability to analyze and solve problems. It is a kind of teaching method been widely used in many course.

The author also tried to use the case teaching in auditing teaching, but the effect is not ideal. After a series theoretical analysis, we believe that the audit case teaching existing main problems are:

First, the teaching time is limited. Most colleges and universities specialized in finance or accounting audit class design for 64 periods or 96 periods (two semesters). For example, in Tibet University for Nationalities we choose the CPA test teaching counseling, it is very difficult finish all the content using the traditional teaching mode at a term of 68 periods. If used case teaching method, scheduling will be a great challenge. The essence of case teaching method is forcing students to think independently, in one case, the students present respectively from his point of view to analyze the case, present their views, analysis, judgment and measures to solve the problems, and then discuss the whole process, which needs a lot of time.

Second, it is difficult to get the right case. The first premise of success in case teaching method is chosen a suitable audit case. At present domestic some teaching cases came from foreign cases, some is wrote cases by the teacher, some is occurred in domestic securities markets. The problems of foreign case is that the case environment and the actual discrepancy, and teacher designed case is often connected the targeted of the general knowledge, with simple and not comprehensive enough. The domestic actual cases, such as Yin Guang Xia Event, are no longer unable to meet the need of teaching which past too many years.

Third, case teaching needs an adaptive process for the teachers and students. Audit case teaching first puts forward the challenge for teachers, for teachers' knowledge structure and teaching ability, classroom organization ability. At present most of the teachers usually teaching task is very heavy, it is difficult to have enough time to take part in the auditing practice. And practice case teaching experience is another big obstacle. During the Case teaching method, students need to spend much time to do the preparatory work. Due to time limit, case teaching discussion on behalf of each or speech general by grouping way, the results showed that each speech has the same point of view in the same case. The mainly reason is the students have already been used to collect data, sharing, not independent thinking in the network era.

Simulation Experiment Teaching Method. Simulation experiment teaching method simulates the real working environment and work task in the laboratory, which is let the students operation completely. This kind of teaching method is focus on students' practical skills training, for laying the foundation to the actual work.

From the teaching point of view, the challenge of auditing simulation experiment teaching as follows:

The main problems of audit simulation is mainly a debugging prevent disadvantages of the type of account based audit training. The modern enterprise fraud technique is more and more complicated. It is difficult to find management fraud through the simple audit based audit, so it need auditors comprehensive use of field observation, inquiry, functional certificate, check the tangible assets and program system. But these methods in the current laboratory conditions cannot be achieved. Audit simulation basis material is difficult to get, so we are in accounting simulation based on the basis of the audit, the existing materials mainly for accounting simulation design, which can't satisfy the requirements of the audit. The evaluation of experimental results is very difficult to achieve. Hard workload is seldom to be objective for a thick this audit working paper carries on grading by different group. In view of this problem we take the classification point scoring method, but it's hard to do for the experimental group in different members of the evaluation is to distinguish.

Practical Teaching Method. Practical teaching method is the student to practice in the accounting firm, enterprise or business the unit accounting, auditing department. The students can directly contact the real audit business, making up for the deficiency of the simulation laboratory auditing. 
Practical teaching method just let students to take part in the company of an audit process of financial statements, participating in the discussion of the project team. It also can improve students' ability of the overall grasp of professional judgment. But $b$ the business are not ripe students practice generally for they can't give enterprises to improve efficiency, and increased the training unit guidance work. So the general unit is not willing to accept students' practice. Especially the scale of students in schools accounting professional is larger now, it is difficult to organize collective practice through the school. And many firms can accept the a little number of students. Therefore, at present the external training usually by the students themselves through all kinds of social relationships in the unit, and the training process is out of control in this case.

How use These Methods in Auditing Teaching Uniformly. The basic content of auditing courses is the auditing basic theory and practice auditing method. Through the above analysis, it can be concluded it is difficulty to achieved satisfactory results only using the any teaching method respectively.

So we chose a new method that is uniform the three methods organically. During the limitation of class periods, we think that auditing course teaching should be priority to lectures, quoting case analysis appropriately, that is arrange a comprehensive case analysis, ahead of 2 to 3 weeks to decorate with students, 4 to 6 hours organization students discuss and summarize, improving the students' ability to analyze the problem.

We established an audit laboratory which reflect the real situation, at least prepare several sets of certified public accountants auditing, introducing the government auditing and internal audit process documents, at the same time making multimedia audio-visual material, strengthen the student's visual sense.

At the same time we strengthen the collaboration of school and enterprise, establishing a series of practice bases. We divided the students into many groups about $5 \sim 8$ person, arranging them in different practice bases by turns. And we have hired an accounting firm of certified public accountants, enterprise financial personnel as long-term part-time practice guidance teachers, to strengthen students' practice guidance and management.

Furthermore we strengthen the construction of teachers' team for auditing practical teaching, taking turns to arrange the teacher to the accounting firm practice, and organize workers to write suitable simulation data.

Students have increased their studying passion, and the effect of teaching was improved by carrying out the measures above.

\section{Conclusion}

It is obviously to see that using these methods uniformly help students understand and master auditing course knowledge and improve students' study interest and enthusiasm. Meanwhile it also could increase the students' practical experience, and enhance the students' capacity of doing it by hand. This is an effective method to cultivation of application-oriented talents.

\section{Acknowledgement}

This research was financially supported by the Social Science Youth Foundation of Tibet Institution for Nationalities (Grant NO. 11myQ14)

\section{References}

[1] Sh. Q. Liu, Research on the Auditing Teaching Model Based on Practical Core. Accounting communication. vol.7, PP 39-41, 2013

[2] W. J. Zhang, The Problems and Countermeasures of Auditing Education in Universities. Chinese market. vol.13, PP 81-82, 2013 
[3] R. Zhu, College audit teaching methods reform. Science and Education. vol.6, PP 175-204, 2014

[4] Y. Chang, On the Construction of Innovative Auditing Teaching System. Financial supervision. vol.35, PP 57-58, 2014

[5] D. M. Fu, A Probe into the Ways to Improve the Teaching Quality of Auditing. Oriental corporate culture. vol.9, PP 252, 2014

[6] H. Zhang, Discussion on Teaching Method of Auditing. Statistics and Management. vol.3, PP 167-168, 2014

[7] M. H. Quan, The Application of Cooperative Learning Method in Auditing Teaching. Finance and Economics. vol.8, PP 239, 2014

[8] . Han, On the Teaching Reform of Auditing. Modern Economic Information. vol.24, PP403, 2015

[9] X. L. Chen, Research on Teaching Reform of Auditing Based on Application - oriented Undergraduate Construction. Times Finance. vol.29, PP 194-195, 2016

[10] N. Feng, A Summary of the Teaching Method of Auditing. Accounting learning. vol.10, PP 245-246, 2016 